\title{
Las compañías con propósito especial de compra o special purpose acquisition companies (SPAC) en Colombia
}

DOI: http://dx.doi.org/10.15425/2017.515

\section{Resumen}

Las compañías con propósito especial de compra (SPAC, por su sigla en inglés) constituyen un mecanismo de financiación a través del cual se capta dinero del público por medio de una emisión primaria de acciones en el mercado público de valores, con el objetivo de entrar en un proceso de fusión o adquisición con una empresa cerrada en un periodo determinado. Este artículo explora la definición, la historia, las características, el funcionamiento y los beneficios de esta figura a partir del desarrollo de esta institución en el derecho anglosajón, al tiempo que analiza la posibilidad y la forma en la que esta compañía podría llegar a ser utilizada en el derecho colombiano.

\section{Palabras clave}

Mercado de valores, emisión primaria de acciones, sociedades por acciones simplificadas, régimen bursátil. 


\title{
The special purpose acquisition companies (SPAC) in Colombia
}

\begin{abstract}
The special purpose acquisition companies (SPAC) are a type of shell companies used for raising capital through an initial public offering (IPO) and aimed to merge with closely held company using the proceeds resulting from the IPO. This article explores the definition, history, characteristics, operation and benefits of this figure from its development in the common law and analyzes if it is possible to use this type of company in Colombia and the way to do it.
\end{abstract}

\section{Keywords}

SPAC, securities market, initial public offering, corporations, securities regulation. 


\section{Introducción}

Los mercados económicos y financieros, en general, gozan de ciclos que, en condiciones relativamente regulares, mantienen una tendencia estable a lo largo de los años. En situaciones excepcionales, cuando en los escenarios de intercambio de productos y servicios se reúnen determinadas circunstancias y condiciones particulares, provocadas por el funcionamiento inherente a los mercados o por factores exógenos a estos, se producen rupturas que cambian la tendencia que hasta ese punto tenían dichos escenarios ${ }^{1}$.

En los mercados financieros y, dentro de estos, en el mercado de valores, unas de las situaciones excepcionales que ocasionan un cambio en el funcionamiento usual de los escenarios de intercambio son las crisis económicas. Cuando las crisis financieras aquejan a los mercados de valores y cambian el comportamiento de estos, quienes intervienen como agentes de estos se ven obligados a encontrar alternativas para ajustarse al nuevo rumbo del mercado. En este contexto, la innovación aparece como una consecuencia obligada de la necesidad de acoplarse a los mercados que han tomado un nuevo curso.

Durante de la década que transcurrió entre 1980 y 1990, la crisis derivada de la política desinflacionaria de la Reserva Nacional de Estados Unidos cambió la tendencia del mercado financiero estadounidense, desatando así un nuevo ciclo de innovación. En ese contexto, los agentes del mercado de valores crearon las compañías con propósito especial de compra o compañías de adquisición de propósito especial ${ }^{2}$, denominadas en inglés special purpose acquisition companies (SPAC) ${ }^{3}$, como un mecanismo encaminado a propulsar el mercado de valores en reemplazo de las ofertas públicas de valores tradicionales, cuyo uso caía debido a la crisis.

Estas sociedades, que se crearon en el periodo de recesión económica, recientemente regresaron al mercado de valores a ocupar un papel protagónico, constituyéndose como uno de los instrumentos de inversión y financiación más atractivos en la actualidad. El uso de esta figura, que se ha venido expandiendo en

$1 \quad J o h n n y$ Jansen van Rensburg y Gary van Vuuren, "Evaluating investment decisions based on the business cycle: A South African sector approach", Cogent Economics \& Finance 8, n. ${ }^{\circ}$ (2020): 3, https://doi.org/10.1080/23322039.2020.1852729

2

Juan Mascareñas, "Compañía de Adquisición de Propósito Especial (SPAC)", Monografías de Juan Mascareñas sobre Finanzas Corporativas working paper, (abril 2021): 1, https://dx.doi.org/10.2139/ ssrn.3824785

3 También son denominadas specified purpose acquisition company. "David Alan Miller", Graubard Miller. https://www.graubard.com/attorney/miller-david-alan/ 
el mundo, es el que se estudiará en el presente escrito, en el cual se analizará la posibilidad de usar este tipo de compañías en Colombia.

Para ello, el estudio se compone de tres partes. La primera explica y analiza la definición, historia, características y funcionamiento de estas compañías, así como los beneficios y desafíos que se pueden derivar de su uso. En la segunda se analiza la existencia de las SPAC en Colombia, el tipo de emisores que pueden o podrían constituirlas, el papel de las sociedades por acciones simplificadas (SAS) como posibles vehículos para ello y los retos de su utilización en el país. La última parte presenta las conclusiones a las que se puede llegar luego del análisis descrito.

\section{Las compañías con propósito especial de compra, special purpose acquisition companies o SPAC: definición, historia, características, funcionamiento y beneficios}

El punto de partida para realizar un análisis como el propuesto inicia por la necesidad de comprender bien el alcance y contenido de esta figura. Para ello, en esta primera parte del estudio se desarrollarán los siguientes puntos: (1) la definición de SPAC; (2) su historia; (3) sus características; (4) su funcionamiento; y (5) sus beneficios y retos.

\section{A) Definición de SPAC}

Las SPAC son sociedades comerciales que se constituyen para captar recursos del público a través de emisiones primarias de acciones en el mercado público de valores, con el objetivo de adquirir negocios o empresas que se identifican o determinan con posterioridad a la oferta pública de valores, 5 .

Las SPAC son definidas y matizadas de diferentes maneras. Sin embargo, para dar una noción general y comprensiva del alcance de esta figura, resulta

Brenda Lenahan, Mariam Boxwala, Ramey Layne, Terry Bokosha y Zach Swartz. "Special purpose acquisition companies: An introduction", The Harvard Law School Forum on Corporate Governance, 6 de julio del 2018. https://corpgov.law.harvard.edu/2018/07/06/special-purposeacquisition-companies-an-introduction/

5 Michael D. Klausner, Michael Ohlrogge y Emily Ruan, "A sober look at SPACs”, European Corporate Governance Institute-Finance Working Paper, n. ${ }^{\circ}$ 746/2021 (abril 2021): 6, https://dx.doi.org/ 10.2139/ssrn.3720919 
relevante mencionar algunas de las definiciones que, debido a su claridad y origen, pueden llegar a ser pertinentes para el estudio propuesto. Dentro de todas ellas, se muestra interesante estudiar: (1) algunas definiciones doctrinarias de las SPAC, y (2) algunas definiciones de autoridades especializadas en el mercado público de valores sobre estas.

\section{Definiciones doctrinales de SPAC}

Debido a que las SPAC son una figura relativamente novedosa, y a que su empleo se ha dado de manera focalizada en determinados mercados públicos de valores, no existe bibliografía abundante que la defina en la doctrina. A pesar de ello, algunos autores han procurado elaborar algunas definiciones, aun cuando no existe norma que las regule expresamente. Para presentar un contraste de las posibles nociones que se han dado sobre las SPAC, a continuación, se reseñarán las definiciones elaboradas por: (1) Kamal Ghosh Ray y Sangita Ghosh Ray; (2) Frederick D. Lipman, y (3) Michael Klausner, Michael Ohlrogge y Emily Ruan, quienes han sabido reseñar y compilar algunos de los elementos más importantes de esta figura.

En primer lugar, Kamal Ghosh Ray y Sangita Ghosh Ray definen las SPAC de la siguiente manera:

Una compañía con propósito especial de compra (SPAC) es una compañía recién constituida que cotiza en el mercado público de valores, que no tiene activos operacionales o un negocio en marcha, asemejándose a una empresa instrumental ${ }^{6}$.

Por otro lado, Frederick D. Lipman, en un estudio de las SPAC como instrumento para realizar emisiones en el mercado público de valores y financiar operaciones de fusiones y adquisiciones, define este tipo de instrumentos de la siguiente manera:

Una SPAC es una compañía "cheque-en-blanco" cotizada públicamente, formada con el propósito de realizar una combinación empresarial con un negocio en

Traducción libre del autor. La expresión empleada en el texto original para referir a las "empresas instrumentales" es shell corporation, que en castellano se suele traducir como "empresas fantasma", "empresas ficticias", "empresas de fachada" o "empresas pantalla". Con frecuencia estos términos se usan para denotar actividades ilícitas, sin que ese sea el caso de las SPAC, que son totalmente lícitas en dichos mercados. Por esta razón, para efectos de la traducción se prefiere el término "empresa instrumental" o "empresa vehículo". Además, se debe aclarar que el término shell company es una noción legal que se encuentra definida, para el caso estadounidense, en el artículo 405, parte 230 del Título 17 del Código de Regulaciones Federales de Estados Unidos (CFR, por su sigla en inglés), el cual recoge en su contenido al Securities Act de 1933. Sydney Finkelstein y Cary L. Cooper, eds. Advances in Mergers and Acquisitions (Bingley: Emerald Publishing Limited, 2017): 83-84. 
marcha indeterminado. Una fusión de una empresa privada con una SPAC o una subsidiaria de la SPAC es un método para que una empresa privada se convierta en pública?

Finalmente, Michael Klausner, Michael Ohlrogge y Emily Ruan definen a las SPAC como "[...] vehículos de inversión pública creados para fusionarse con compañías cerradas, para volverlas públicas"8.

Como se puede advertir de estas tres definiciones, las SPAC son compañías que no tienen un negocio en marcha ${ }^{9}$, que se crean e inmediatamente se llevan al mercado público de valores para que, por medio de una emisión primaria, se capten recursos de capital y con estos se adquiera una o varias compañías que hacen parte del mercado privado.

En los términos de la definición, estas sociedades hacen parte de un género que se denomina "compañías cheque-en-blanco" o blank-check companies ${ }^{10}$. De acuerdo con la Comisión de Valores de Estados Unidos, denominada en inglés U.S. Securities and Exchange Commission (SEC), estas sociedades son "compañías en etapa de desarrollo que no tienen un plan o propósito de negocio específico o que han señalado que su plan de negocios es entrar en una fusión o adquisición con una compañía o compañías indefinidas, otras entidades o personas" ${ }^{11}$. Estas últimas empresas, que como se señaló constituyen un género al que pertenecen las SPAC, hacen ofertas públicas en el mercado de valores para recaudar recursos en el mercado desintermediado, con la particularidad de que "[u]na oferta blank check es una oferta pública inicial de una compañía que se ha formado con el propósito de recaudar dinero y comprar una empresa ya existente"12 $y$, debido a que con ellas se busca captar recursos para llevar a cabo una fusión o adquisición, cuentan con la

$7 \quad$ Traducción libre del autor. Frederick D. Lipman, International and US IPO planning: A business strategy guide (Hoboken: John Wiley \& Sons, Incorporated, 2008), 203.

$8 \quad$ Klausner, Ohlrogge y Ruan, "A sober look at SPACs", 6.

$9 \quad$ No se debe confundir con las compañías no operativas que se encuentran reguladas por el artículo 144 de la Ley 1955 del 2019 y por el Decreto 1068 del 2020.

10 Estas compañías se encuentran definidas en el artículo $77 \mathrm{~g}(\mathrm{~b})(3)$ del título 15 United States Code [15 USC $\S 77 \mathrm{~g}(\mathrm{~b})(3)$ ] de la siguiente manera: “(3) For purposes of paragraph (1) of this subsection, the term "blank check company" means any development stage company that is issuing a penny stock (within the meaning of section $78 c(a)(51)$ of this title ) and that- $(A)$ has no specific business plan or purpose; or (B) has indicated that its business plan is to merge with an unidentified company or companies".

11 Traducción libre del autor. "Blank Check Company", U.S. Securities and Exchange Commission. https://www.investor.gov/introduction-investing/investing-basics/glossary/blank-check-company

12 Derek K., Heyman, "From Blank Check to SPAC: The Regulator's Response to the Market, and the Market's Response to the Regulation", Ohio State Business Law Journal 2, n. 1 (2007): 533. 
posibilidad de hacer emisiones de acciones cuyo valor sea inferior a cinco dólares estadounidenses (USD 5), a las cuales se les conoce como penny stocks ${ }^{13}$.

En general, las blank check companies pueden ser de diferentes tipos, de acuerdo con el vehículo que se utilice para dicha finalidad. Sin embargo, en términos generales, estas sociedades se pueden clasificar en dos grupos muy concretos, que son: (1) las que se encuentran sujetas a la Regla 419 (Rule 419), y (2) las que no se encuentran sometidas a dicha regulación, como lo son las SPAC ${ }^{14}$. Esta última circunstancia, que se explorará más adelante, es una de las ventajas más importantes con las que cuentan las SPAC, pues el hecho de que no estén sometidas al artículo 230.419 (§ 230.419)15 del título 17 del Code of Federal Regulations, hacen de estas un instrumento muy atractivo para captar dinero en el mercado público de valores. Por lo pronto, basta señalar que las SPAC son blank check companies que no se encuentran reguladas por la Regla 419 y que, como se indicó, constituyen empresas instrumentales a través de las cuales se capta dinero en el mercado público de valores por medio de una oferta pública inicial para comprar una compañía cerrada ya existente con el producto de dicha captación.

\section{Definiciones de autoridades especializadas}

Al paso que la doctrina presenta algunas de las definiciones más valiosas de las SPAC, las autoridades especializadas en el mercado público de valores dan una definición propia de estas compañías. Dentro de estas últimas, resulta interesante estudiar las elaboradas por: (1) la SEC; y (2) la Financial Industry Regulatory Authority (o Finra), esto es, la autoridad de autorregulación más importante del mercado público de valores estadounidense.

De conformidad con la SEC, la SPAC es una especie de blank check company "que se crea específicamente para agrupar recursos para financiar una oportunidad de fusión o adquisición dentro de un periodo determinado. Usualmente, la oportunidad [de fusión o adquisición] está por ser definida"16. Por su parte, la Finra define a las SPAC como "empresas instrumentales que captan capital en emisiones

Derek K., Heyman, "From blank check to SPAC", 533.

Lipman, International and US IPO, 203.

Se debe tener presente que en Estados Unidos los artículos se denominan secciones y se identifican con el símbolo $\S$.

"Blank check company". 
públicas iniciales de valores (IPOs) con el propósito de fusionarse o adquirir una empresa en marcha"17.

\section{Definición de SPAC}

A partir de las definiciones transcritas se puede decir que las SPAC son compañías instrumentales que no tienen un negocio en marcha, y que se constituyen con el único objetivo de realizar una captación de dinero a través de una oferta pública inicial en el mercado público de valores, en específico, para que con los recursos recaudados con la emisión se adquiera, dentro de un plazo determinado, una empresa privada cuyo negocio en marcha es atractivo para los patrocinadores de la SPAC.

\section{B) Historia de las SPAC}

La historia de las SPAC se compone de dos partes, cada una de las cuales se explica a continuación.

\section{Nacimiento de las SPAC}

Las SPAC nacieron en 1990 como resultado de un trabajo conjunto realizado por David Nussbaum, entonces directivo de GKN Securities ${ }^{18}$ y hoy director de EarlyBirdCapital, y David Alan Miller, abogado de la Universidad de Nueva York y socio de la firma de abogados Graubard Miller ${ }^{19}$. Estos dos empresarios, en la década de los noventa, cuando Estados Unidos salía de una recesión económica derivada de la crisis de los ochenta y el número de emisiones iniciales de valores en el mercado público decrecía considerablemente debido a la caída en la economía, vieron una oportunidad de negocio en una de las excepciones aplicables a las emisiones de valores realizadas bajo la Rule 419 ya citada ${ }^{20}$.

La idea de Nussbaum y Miller consistió en hacer emisiones de valores de empresas instrumentales que tuvieran más de 5 millones de dólares en activos o que

\footnotetext{
17 "Regulatory Notice 08-54. Guidance on Special Purpose Acquisition Companies", Finra. https:// www.finra.org/rules-guidance/notices/08-54

18 Daniel S. Riemer, "“Special Purpose Acquisition Companies: SPAC and Span, or Blank Check Redux"," Washington University Law Review 85, n. 4 (2007): 945.

19 David N. Feldman, Regulation A+ and other alternatives to a traditional IPO: Financing your growth business following the JOBS act (Hoboken, New Jersey: John Wiley \& Sons, 2018), 109. 
buscaran captar más de 5 millones de dólares en una oferta pública inicial de valores $^{21}$ y que, por este motivo, se encontraren por fuera de la regulación prevista en la Rule 419, al tiempo que adoptaban voluntariamente muchos de los requerimientos establecidos en dicha regla para atraer inversionistas de todo tipo ${ }^{22}$. Bajo esta estructuración, si bien en la emisión las compañías no tenían que: (1) depositar el dinero captado a una cuenta fiduciaria (trust) o de depósito (escrow account), (2) poner un límite temporal para completar el negocio de fusión o adquisición perseguido, (3) afectar algunas acciones a un depósito, y (4) reconfirmar con los accionistas su aprobación antes de cerrar una fusión en reversa (reverse merger) -considerada en Colombia como una fusión por absorción ${ }^{23}$-, las empresas lo hacían de manera voluntaria para atraer inversionistas.

De esta manera, Nussbaum lograba estructurar emisiones de compañías instrumentales, sin tener las limitaciones previstas en la Rule 419, pero con el atractivo de adoptarlas voluntariamente y de aprovechar la posibilidad la existencia de las compañías "cheque-en-blanco" o blank check companies para emitir acciones, captar capital, buscar un negocio en marcha atractivo en un periodo promedio de dos años, y de participar de ese negocio a través de una fusión o una adquisición o de restituir el dinero captado a los inversionistas en una proporción equivalente al $92 \%$ ○ $95 \%$ del valor de la inversión, si no se lograba una fusión o una adquisición exitosa ${ }^{24}$. Bajo estas reglas, entre 1993 y 1994 Nussbaum llevó a cabo 13 emisiones de blank check companies bajo la estructura de lo que él mismo llamaría SPAC, 12 de las cuales culminarían exitosamente con la fusión o la adquisición que se había propuesto en el prospecto de información de manera general e indeterminada ${ }^{25}$.

La regla establece que estarán exceptuadas de la Rule 419 las emisiones que hagan empresas con más de 5 millones de dólares en activos o que busquen captar más de 5 millones de dólares a través de una emisión pública. Para el último caso, las SEC exige que la emisión de los valores sea por medio de un underwriting garantizado o en firme y no al mejor esfuerzo. Feldman, Regulation + and other, 109.

Riemer, "Special purpose acquisition companies", 945.

La fusión en reversa (reverse merger), también llamada backdoor listing, consiste en la fusión de una empresa privada con una compañía listada en bolsa, normalmente una shell company, que se lleva a cabo con el objetivo de hacer pública a la empresa privada, en este caso, sin tener que cumplir con los requisitos tradicionales de una emisión primaria de valores (IPO, por su sigla en inglés). En Colombia, este tipo de fusiones se enmarcaría dentro de las fusiones por absorción, de conformidad con lo establecido en el artículo 172 del Código de Comercio. Vinod Kumar y Priti Sharma, An insight into mergers and acquisitions: A growth perspective (Singapur: Springer Singapore Pte. Limited, 2019), 8-9. 


\section{Resurgimiento de las SPAC}

En la medida en que el mercado de valores retornó a las ofertas públicas iniciales de valores tradicionales como un instrumento de financiación, concluyendo de esta manera un ciclo en su funcionamiento ${ }^{26}$, las SPAC dejaron de utilizarse durante un tiempo. Sin embargo, a principios del 2003, estas compañías volvieron a resurgir, en lo que podría denominarse la segunda generación de SPAC.

En el 2003, impulsado en buena medida por Nussbaum, quien estructuraría más de 70 ofertas públicas de valores a través de las SPAC, se presenció un nuevo crecimiento en las emisiones de valores a través de estas compañías ${ }^{27}$, el cual continuaría hasta la crisis económica del 2008, para resurgir nuevamente en el 2014.

Esta segunda faceta de las SPAC, que tuvo lugar entre el 2003 y el 2008, fue realmente significativa para el mercado público de valores. Durante este periodo se estructuraron más de 150 SPAC, 70 de las cuales completaron exitosamente la fusión o la adquisición que se habían propuesto ${ }^{28}$. Dentro de las diferentes SPAC, la mayoría de ellas captaron 100 millones de dólares o menos, para sumar en su conjunto un valor aproximado de 1,6 billones de dólares para el 2007. La menor parte de ellas, que consistió en aquellas cuyas emisiones superaban los 100 millones de dólares, hicieron una captación equivalente a 10 billones de dólares para el 2007, que para el 2008 se reduciría a 4,3 billones $^{29}$.

Este crecimiento de las SPAC en el mercado se debió a diferentes motivos. Dentro de ellos, además de los beneficios económicos y de inversión que representaba esta figura, la administración de las SPAC se volvió uno de los atractivos más llamativos de estas compañías. En efecto, las SPAC se convirtieron en un negocio administrado únicamente por los hombres de negocios más reputados y exitosos de Estados Unidos y del mundo. Así, dentro de los muchos nombres que se sumaron a la administración de las SPAC, algunos de los más resonados, inclusive hoy en día, son: (1) Chamath Palihapitiya, antiguo ejecutivo de Facebook y actualmente conocido como "El rey de las SPAC" ${ }^{30}$; (2) Steve Wozniak, cofundador de Apple;

26 Como lo afirma la doctrina, las IPO tienen ciclos de vida de acuerdo con el tipo de IPO que se trate. Paul Rose y Steven Davidoff Solomon, "Where have all the IPOs gone: The hard life of the small IPO," Harvard Business Law Review 6, n. 1 (Winter 2016): 83-84.

27 "Principals", EarlyBirdCapital. https://www.earlybirdcapital.com/about/principals

28 David N. Feldman, Reverse mergers: And other alternatives to traditional IPOs (Nueva York: John Wiley \& Sons, 2009), 210-211.

29 Feldman, Reverse mergers, 210-211.

30 "The king of SPACs wants you to know he's the next warren buffett", Bloomberg, 12 de febrero del 2021, https://www.bloomberg.com/news/articles/2021-02-12/the-king-of-spacs-wants-you-toknow-he-s-the-next-warren-buffett 
(3) Mario Gabelli, fundador de Gamco Investors Inc.; (4) Ronald Perelman, presidente de Revlon; (5) Dan Quayle, vicepresidente de los Estados Unidos durante el gobierno de George H. W. Bush; y (6) Nelson Peltz, presidente de Trian Fund Management ${ }^{31}$.

Sin embargo, esta segunda fase de las SPAC, que constituiría su primer resurgimiento en el mercado de valores, se vería obstaculizada por la crisis económica del subprime en el 2008. A partir de la crisis, y como consecuencia de la desaceleración y el resquebrajamiento de la confianza del público en el mercado de valores, el uso de las SPAC como vehículos de inversión y financiamiento decrecería de manera importante. A pesar de ello, a principios del 2014, en lo que podría llamarse una tercera etapa de las SPAC, este mecanismo se volvió a utilizar como un instrumento de inversión. Este nuevo cambio, que afirman algunos se debió al fortalecimiento del mercado de renta variable y a la creación de una nueva estructura de las SPAC que era producto del acuerdo de las bolsas de valores y los estructuradores ${ }^{32}$, volvió a poner en el mapa a las SPAC, esta vez, para hacer emisiones de tamaños y características como nunca se habían visto.

En efecto, a partir del 2014 las SPAC han tenido un crecimiento importante, al punto que se han convertido en uno de los negocios más atractivos para muchos inversionistas. Dentro de las transacciones más importantes que se han realizado mediante estas compañías, algunas de ellas se reseñan en el siguiente cuadro:

\begin{tabular}{|c|c|c|c|}
\hline SPAC & Monto & $M \& A$ & Año \\
\hline $\begin{array}{l}\text { Pershing Square } \\
\text { Tontine Holdings }\end{array}$ & $\begin{array}{l}\text { USD } 4 \\
\text { billones }\end{array}$ & $\begin{array}{l}\text { Busca fusionarse con un unicornio, es decir, un } \\
\text { emprendimiento o startup company valuada en } 1 \text { o } \\
\text { más billones de dólares. }\end{array}$ & 2020 \\
\hline $\begin{array}{l}\text { Churchill Capital } \\
\text { Corp III }\end{array}$ & $\begin{array}{l}\text { USD } 1 \\
\text { billón }\end{array}$ & $\begin{array}{l}\text { Se fusionó con MultiPlan Corp., una empresa del } \\
\text { sector salud, en una transacción de USD } 11 \text { billones. }\end{array}$ & 2019-2020 \\
\hline Virgin Galactic & $\begin{array}{l}\text { USD } 480 \\
\text { millones }\end{array}$ & $\begin{array}{l}\text { Se utilizó para llevar a la empresa Virgin al mercado } \\
\text { público de valores. El objetivo de la SPAC es comprar } \\
\text { o intercambiar (swap) acciones con otros negocios } \\
\text { relacionados con viajes, servicios financieros, salud } \\
\text { y tecnología. }\end{array}$ & 2020 \\
\hline $\begin{array}{l}\text { VectolQ } \\
\text { Acquisition Corp. }\end{array}$ & $\begin{array}{l}\text { USD } 525 \\
\text { millones }\end{array}$ & $\begin{array}{l}\text { Se fusionó con la empresa Nikola, una compañía } \\
\text { automotriz estadounidense. }\end{array}$ & 2020 \\
\hline $\begin{array}{l}\text { Diamond Eagle } \\
\text { Acquisition }\end{array}$ & $\begin{array}{l}\text { USD } 350 \\
\text { millones }\end{array}$ & $\begin{array}{l}\text { Se fusionó con la empresa DraftKings, una empresa } \\
\text { de apuestas deportivas. }\end{array}$ & 2019 \\
\hline
\end{tabular}

Tabla 1. Las SPAC más significativas de los últimos años

Fuente: elaboración del autor.

31 "The king of SPACs wants you to know".

32 Feldman, Regulation A+ and other, 114. 
La tendencia al uso de las SPAC como vehículos de inversión o como mecanismos a través de los cuales una empresa puede convertirse en pública, ha venido incrementando considerablemente. A partir del 2015, el número de SPAC por año empezó a aumentar considerablemente, con un leve retroceso en el 2016. En Estados Unidos se hicieron 20 emisiones de SPAC en el 2015, 13 en el 2016, 34 en el 2017, 46 en el 2018, 59 en el 2019, 248 en el 2020 y 330 en lo corrido del $2021^{33}$. En este último año, para junio, a través de SPAC se habían captado aproximadamente 104.876 millones de dólares en 330 transacciones $^{34}$.

Como se puede observar, las SPAC son instrumentos propicios para la inversión y financiación, inclusive en tiempos de crisis económicas y sanitarias como las provocadas por el COVID-19. De hecho, si se analizan los datos presentados, el 2021 ha sido el año con más SPAC en la historia reciente, lo que ha ampliado un mercado que algunos reconocen puede ser de 40 a 50 billones de dólares en Estados Unidos ${ }^{35}$. Tan es así que parecería que incluso el remedio preferencial en las fusiones y adquisiciones para el Departamento de Justicia de Estados Unidos, para septiembre del 2020, serían las SPAC ${ }^{36}$.

Como se puede apreciar, en la actualidad las SPAC constituyen un instrumento muy atractivo para las empresas, los inversionistas y, así mismo, para el mercado de capitales en general.

\section{C) Características}

De lo dicho hasta este punto, se puede decir que la operación que se lleva a cabo a través de una SPAC, y estas mismas, comparten los siguientes rasgos característicos:

1. Son sociedades instrumentales, cuyo objetivo principal es adquirir o fusionarse con una empresa privada que tenga un negocio en marcha atractivo $^{37}$. En esa medida, las SPAC no cuentan con un negocio en

"SPAC IPOs in the U.S. 2009-2021", Statista, 7 de mayo del 2021, https://www.statista.com/ statistics/1178249/spac-ipo-usa/

"SPACDex: Market cap \& equal weighted return", SPACInsider. https://spacinsider.com/stats/

"SPACs have raised $\$ 40$ billion in dry powder, and it's growing daily", RBC Capital Markets. https:// www.rbccm.com/en/gib/ma-inflection-points.page.

36 "Private equity purchasers and SPACs may be 'preferred' divestiture buyers under new DOJ guidelines for merger remedies", The National Law Review. https://www.natlawreview.com/article/ private-equity-purchasers-and-spacs-may-be-preferred-divestiture-buyers-under-new 
marcha y se constituyen solo para captar dinero del público a través de una emisión primaria de acciones en el mercado público de valores.

2. Son sociedades temporales, pues tienen un objetivo de adquisición o fusión que se tiene que concretar y culminar en un periodo relativamente corto, el cual en la mayoría de los casos se encuentra en un rango de 18 a 36 meses.

3. La sociedad es administrada por profesionales expertos que no suelen recibir remuneración por su trabajo sino tan solo con el éxito de la transacción. Por ello, estos proyectos usualmente tienen respaldo en grandes inversionistas de capital, quienes contribuyen con el capital humano para la administración.

4. Los recursos captados del público no pasan al patrimonio de la sociedad directamente, sino que son trasladados a una fiducia o a una cuenta fiduciaria (trust) o de depósito (escrow account), y solo pueden ser utilizados para realizar la transacción de fusión o adquisición respectiva, así como las actividades que sean necesarias para cumplir con dicho objetivo de fusión o adquisición.

5. La existencia de la SPAC termina si no se hace una fusión o una adquisición de una empresa privada en el periodo previsto para ello, en cuyo caso se disuelve y liquida la sociedad respectiva y se reembolsa aproximadamente un $92 \%$ o $95 \%$ de la inversión hecha por los accionistas.

6. Jurídicamente estas empresas hacen parte de una categoría de empresas denominadas blank check companies, que pueden hacer emisiones de acciones cuyo valor sea inferior a cinco dólares estadounidenses sin necesidad de contar con un negocio en marcha.

7. Societariamente se constituyen como compañías de capital, más concretamente, como corporations, típicamente registradas en el estado de Delaware, Estados Unidos; en las Islas Caimán; en las Islas Vírgenes Británicas o en las Islas Marshall ${ }^{38}$.

8. Al proceso de fusión o adquisición se le conoce como De-SPAC y con este se busca concretar la adquisición de un negocio en marcha, para lo cual se requiere de la aprobación de la administración y del voto

reestructuración o reorganización. Este es el caso de Schultze Special Purpose Acquisition Corp., una SPAC que se utilizó para adquirir compañías en esta fase. "Amendment No. 2 to Form S-1 under the Securities Act of 1933", United States Securities and Exchange Commission. https://www.sec. gov/Archives/edgar/data/1754824/000161577418013897/s114444_sla.htm 
favorable de los accionistas que, de no estar de acuerdo con la transacción, se podrán salir de la SPAC recibiendo un reembolso, y

9. Como se trata de una modalidad especial de emisiones de valores, los colocadores cobran de manera diferente el proceso de underwriting. Mientras en una emisión pública de valores tradicional es común que se cobre un descuento de $5 \%$ al $7 \%$ del monto de la emisión, el cual conserva el colocador a título de remuneración, en las SPAC se suele cobrar un $2 \%$ al inicio de la colocación inicial de los valores y un 3,5\% en el momento de cierre de la transacción De-SPAC ${ }^{39}$.

Todos los anteriores son algunos de los puntos fundamentales que caracterizan a este tipo de sociedades instrumentales.

\section{D) Funcionamiento de una SPAC}

En términos generales, el funcionamiento de la SPAC se puede dividir en las siguientes dos fases: (1) la constitución de la sociedad y la captación de los recursos; y (2) el proceso de De-SPAC.

\section{Constitución de la sociedad y captación de recursos}

Lo primero que se debe hacer cuando una empresa va a acudir al mercado público de valores por medio de una SPAC es constituir una sociedad de capitales (corporation), para lo cual deberán redactar sus estatutos (bylaws) y realizar la inscripción en el registro que corresponda. En la práctica, la constitución de estas sociedades instrumentales se ha hecho usualmente en el estado de Delaware en Estados Unidos, en las Islas Caimán ${ }^{40}$, en las Islas Vírgenes Británicas o en las Islas Marshall, en

"Special purpose acquisition companies".

Cabe destacar que la mayoría de las SPAC estructuradas por inversionistas colombianos, o que se han fusionado con sociedades colombianas, se encuentran constituidas en Islas Caimán y están listadas en Nasdaq o NYSE. Ese es el caso de (1) Andina Acquisition Corp. I, II y III, tres vehículos de inversión que se fusionaron o están en curso de fusionarse con empresas colombianas y estadounidenses, y (2) Union Acquisition Corp. II, que adquirió a Procaps Group en el 2021. Además, es muy común que, de acuerdo con el caso, se pacte un cambio de domicilio de la sociedad de las Islas Caimán al Estado de Delaware una vez se concrete la fusión. Sin embargo, si la SPAC es promovida por inversionistas estadounidenses, como es el caso de Schultze Special Purpose Acquisition, que adquirió a la sociedad colombiana Clever Leaves en el 2020, es común que la constitución de la SPAC se haga directamente en el estado de Delaware. 
estos últimos tres casos cuando se tiene proyectado realizar una fusión o adquisición transnacional ${ }^{41}$.

Lo segundo que suele hacer es suscribir un contrato de compraventa de acciones o de valores con el patrocinador (sponsor) ${ }^{42}$, el cual se denomina en inglés securities purchase agreement (SPA) ${ }^{43}$. Esto se hace con el objetivo de garantizar que un porcentaje determinado de la emisión de valores, usualmente equivalente al $25 \%$ de las acciones, sea adquirido por el patrocinador de la transacción, quien además de hacerse a unas acciones, que por lo general se clasifican como acciones de fundador (founder shares), adquiere un warrant que le permite la adquisición de acciones adicionales en el futuro bajo determinados parámetros ${ }^{44}$.

Lo tercero que es común hacer en este tipo de transacciones es celebrar un warrant agreement entre el agente de transferencia y la SPAC. En este acuerdo se fijan los términos en los que se deberán ejercer los warrants y los deberes de inscripción que surgen para la SPAC cuando se ejercen estas "opciones de compra"45.

El cuarto paso a seguir en estas transacciones consiste en la firma de un pagaré (promissory note) por parte de la SPAC y en favor del patrocinador (sponsor). En efecto, para que la SPAC acuda al mercado público de valores y pueda emitir valores por medio de una oferta pública inicial, se tienen que pagar varios montos de dinero, que por lo general corresponden a (1) servicios legales, (2) contabilidad, (3) impresiones y papelería, (4) inscripción en bolsa (p. ej. NYSE y/o Nasdaq ${ }^{46}$ ),

"Special purpose acquisition companies".

La intervención de los patrocinadores o sponsors no era una característica inicial de las SPAC, sino que se añadió en la medida en la que el negocio mostró ser exitoso. Los sponsors son el equipo de administración o gestión de la SPAC y son los encargados de identificar la empresa que se va a comprar o adquirir. En principio a estos sponsors se les compensaba por medio acciones. Hoy en día, debido a que los mismos patrocinadores conciben a las SPAC como una inversión, ellos suelen hacer una inversión en la misma y adquirir unas acciones para participar del negocio de fusión o adquisición que se llevará a cabo con la SPAC. Lipman, International and US IPO, 109-110.

3 En Colombia es común identificar al contrato de compraventa de acciones por su nombre en inglés stock purchase agreement (SPA), el cual, a pesar de identificarse bajo su nombre en inglés, no es otra cosa que un contrato de compraventa de acciones. Este último, a pesar de que constituye una figura típica de la tradición jurídica de derecho civil en Colombia, ha seguido la tradición anglosajona en su redacción, por lo cual, es común que se incorporen términos propios de esa cultura jurídica, como lo son las "declaraciones de causalidad", llamadas en inglés representations and warranties. Diego Muñoz, Privatización en Colombia: marco jurídico para la transferencia de la propiedad estatal (Bogotá: DNP, 2004), 72-129; Néstor Humberto Martínez. Cátedra de sociedades. Régimen comercial y bursátil (Bogotá: Legis, 2020): 667-679.

\footnotetext{
"Special purpose acquisition companies".

"Special purpose acquisition companies".

La Bolsa de Valores de Nueva York (New York Stock Exchange [NYSE]) es un típico mercado transaccional bursátil, considerado jurídicamente como un mercado estandarizado o bursátil. Por el contrario, NASDAQ, si bien en términos prácticos es una bolsa de valores, es considerada parte el mercado mostrador u over-the-counter. Alan R. Palmiter, Securities regulation. Examples \& explanations (Nueva York: Wolters Kluwer, 2017): 348 y 351.
} 
(5) trámites ante las autoridades administrativas o de autorregulación (p. ej. SEC y/o Finra), (6) viáticos de viajes y de promoción, y (7) otros gastos varios ${ }^{47}$. Como la SPAC no cuenta con recursos propios para sufragar estos gastos antes de acudir al mercado público de valores, estos valores son pagados por el patrocinador, bajo el compromiso de que, una vez realizada la oferta pública inicial, se pagarán de vuelta al patrocinador.

En un quinto paso, los patrocinadores o sponsors suelen elaborar documentos que den cuenta de su participación en la SPAC, de manera que quede clara su relación jurídica con ella. Para esto, los fondos de capital privado (private equity funds) y las firmas de inversiones, quienes son indirectamente las que suelen hacer las veces de patrocinadores, constituyen sociedades híbridas, tales como la limited liability company, que toman la calidad de patrocinador directo de la SPAC para efectos de vincularse contractualmente con esta ${ }^{48}$.

En un sexto punto, luego de haber documentado la forma de participación de los patrocinadores en la SPAC, con frecuencia se firman documentos en los que se acuerdan: (1) las obligaciones de los directivos y patrocinadores relacionadas con la forma de votar frente al proceso de De-SPAC, (2) las indemnidades de las SPAC frente a determinadas reclamaciones a cargo de la cuenta fiduciaria o de depósito, (3) la posibilidad de perder las acciones de fundadores en la medida en que no se ejerza la opción de sobreasignación (green shoe) ${ }^{49}$ por parte del colocador (underwriter), (4) entre otras. Todos estos acuerdos se agrupan en un documento denominado letter agreement ${ }^{50}$, cuya traducción al castellano equivaldría a un "acuerdo en forma de carta" ${ }^{51}$, una figura jurídica que agrupa diferentes negocios jurídicos individuales y que no es propia de los sistemas de derecho continental europeo.

47 Para ver los gastos usuales de inscripción en bolsa: José Miguel Mendoza, "Securities regulation in low-tier listing venues: The rise of the alternative investment market”. Fordham Journal of Corporate \& Financial Law 13, n. ${ }^{\circ}$ 2, (2008): 277. https://ssrn.com/abstract $=1004548$

48 "Special purpose acquisition companies".

49 Se llama sobreasignación o green shoe a la posibilidad que se le concede al colocador u underwriter, en el marco de una oferta pública inicial de valores, de vender más valores a los inversionistas de los que se habían planeado colocar inicialmente. Estas opciones llevan su nombre por una emisión de valores realizada por Green Shoe Manufacturing Company en 1919, quien implementó por primera vez esta figura. Hoy en día son muy comunes en los contratos de underwiriting y se ejercen tan solo si la emisión ha sido exitosa. "Greenshoe Option", Investopedia, 26 de octubre del 2020, https:// www.investopedia.com/terms/g/greenshoe.asp

50 "Special purpose acquisition companies".

51 "Comisión de las Comunidades Europeas", EUR-Lex. https://eur-lex.europa.eu/LexUriServ/ LexUriServ.do?uri=COM:2009:0226:FIN:ES:PDF 
En séptimo lugar, la SPAC deberá suscribir un contrato de fiducia o de depósito (escrow account) con una institución financiera para que, una vez realizada la emisión pública de valores, los recursos pasen a esta y sean administrados bajo los parámetros de constitución.

En octavo lugar, se deberán suscribir todos los contratos necesarios para llevar a cabo la emisión pública de valores. Del resultado de todos los negocios jurídicos que se celebran para realizar una emisión en el mercado público de valores, el prospecto de información es el documento más relevante, pues además de que constituye la columna vertebral de la emisión, reviste un carácter particular en el caso de las SPAC. Este último aspecto consiste en que, al no contar con un negocio en marcha y ser tan solo una sociedad instrumental, la revelación de información que se deberá hacer en el prospecto en el caso de la emisión de una SPAC va a ser mucho más concisa y breve, al menos en términos de revelación de información. Esto, como se profundizará más adelante, constituye una ventaja de este tipo de figuras del mercado público de valores, pues permite llevar a cabo emisiones con una carga más leve respecto a la revelación de información.

Finalmente, en la estructuración de la SPAC se celebran otros tipos de acuerdos relacionados principalmente con: (1) los derechos de registro, (2) otros tipos de warrants, (3) el pago con acciones de la SPAC a los directivos y administradores de esta, (4) las indemnidades de sus directivos, y (5) los servicios administrativos y de infraestructura requerida para el desarrollo de la SPAC ${ }^{52}$.

\section{El proceso de De-SPAC}

Como se mencionó, cuando una SPAC lleva a cabo una emisión de acciones, en el prospecto de información no precisa ni singulariza las empresas que va a adquirir, puesto que, además de que esto la exime de tener que revelar mucha más información en dicho documento, en el momento de la emisión inicial de valores no se sabe con claridad la empresa que se va a adquirir o, como también puede ocurrir, no se quiere revelar su nombre.

Al paso que la primera fase de estructuración de la SPAC implica un proceso que típicamente corresponde a una operación del mercado de valores, en la medida en la que se requiere de la estructuración de todo el andamiaje necesario para hacer una oferta pública inicial, la segunda fase del negocio de una SPAC, si se cumple con el objetivo de adquisición propuesto, se constituye como una operación de 
fusión o adquisición típica. Por este motivo, una vez se ha identificado la empresa que se va a adquirir, se deberá seguir el proceso que, por lo general, se lleva a cabo cuando se van a fusionar dos compañías. Por lo anterior, en este proceso se verificarán, generalmente, los siguientes pasos:

1. Etapa de negociación. Identificado el negocio, será labor de la administración y de los directivos de la SPAC ponerse en contacto con quienes serán vendedores en el contrato de compraventa de acciones (SPA, por su sigla en inglés) de la sociedad objetivo (target). Para ello, se entra en una fase precontractual a la que se le suele denominar como tratativas, prenegociación o puntuación ${ }^{53}$. En esta fase no existe todavía una oferta o un negocio jurídico, sino tan solo una comunicación para iniciar unas negociaciones.

2. Celebración de acuerdos de confidencialidad. La revelación de información sobre diferentes aspectos del negocio que se va a adquirir o con el cual se va a fusionar es un aspecto crucial de todo proceso de integración empresarial. En la medida en que la sociedad vendedora debe revelar información importante de su negocio, así como de determinadas personas que se relacionan con este, se debe garantizar que quienes intervienen en la negociación y, por ello, tienen acceso a la información que puede ser confidencial o delicada, no la revelen al público. Para garantizar la confidencialidad de la información que será suministrada a la SPAC durante el proceso de debida diligencia (due diligence), la empresa objetivo de la fusión o adquisición celebrará un acuerdo de confidencialidad (en inglés, non-disclosure agreement o NDA) con la SPAC, de manera tal que pueda suministrar la información que corresponda, con la seguridad que no habrá un escape de información como consecuencia del proceso o que, si lo llegare a haber, tendrá el derecho a ser indemnizada por ello.

3. Firma del term sheet, la carta de intención o el memorando de entendimiento. Para llegar a un acuerdo, la SPAC y la sociedad objetivo pueden suscribir una hoja de plazos y condiciones (term sheet), una carta de intención (letter of intent) o un memorando de entendimiento (memorandum of understanding). La primera establece, a manera de 
resumen, los principales rasgos del negocio de compra ${ }^{54}$. La segunda fija, en términos generales, la "voluntad de adelantar tratos preliminares para explorar la posibilidad de celebrar uno o más contratos, y puede además contener una propuesta sobre cuándo y cómo llevar a cabo los tratos preliminares" 55 . El último, de manera semejante, consiste en un documento preliminar que contiene un acuerdo inicial alcanzado por las partes sobre algunos aspectos puntuales de la transacción prospectiva ${ }^{56}$.

4. Celebración de acuerdos de debida diligencia (due diligence agreement, en inglés). Como lo señala la doctrina, los acuerdos de debida diligencia son pactos en los que se acuerda la forma en la que se adelantará el suministro y análisis de información relevante dentro de un proceso de contratación ${ }^{57}$. Por lo general, estos acuerdos son cláusulas que se incluyen en cualquiera de los documentos mencionados con anterioridad. El proceso de debida diligencia suele dividirse en las siguientes etapas: (1) envío y recepción inicial de información y documentos, los cuales se allegarán voluntariamente por la empresa objetivo o como respuesta a un requerimiento o listado de preguntas que suele hacer el equipo de auditoría respetivo, bien sea directamente o a través de la compañía adquirente; (2) estudio preliminar de la información y solicitud de información y documentación adicional, lo cual se hará una vez se hubiere hecho un análisis inicial de la información allegada por la empresa objetivo y solo en la medida en la que se requiera conocer a profundidad algunos aspectos adicionales; (3) visitas a las sedes y a los cuartos de datos de la empresa objetivo, y (4) reporte final de debida diligencia, el cual deberá contener, entre otras cosas, un resumen ejecutivo que sintetice de los hallazgos encontrados por el equipo de

"Term sheet overview", Corporate Finance Institute. https://corporatefinanceinstitute.com/re sources/templates/transactions/term-sheet-guide/

Cabe anotar que esta finalidad, como bien lo señala el profesor Juan Carlos Varón Palomino, tan solo constituye el alcance básico que se puede y suele dar a la carta de intención. Sin embargo, vale la pena precisar que la complejidad de estos negocios variará caso por caso. Juan Carlos Varón Palomino, "Cartas de intención, memorandos de entendimiento, acuerdos de confidencialidad y acuerdos de debida diligencia, como fuentes de obligaciones en Colombia: apuntes desde la teoría del acto o negocio jurídico y de la formación del contrato", Anuario de Derecho Privado, n. ${ }^{\circ} 1$, (2019): 162, http://dx.doi.org/10.15425/2017.200 
análisis respectivo y una serie de alertas relacionadas con los riesgos que puede acarrear la transacción para el comprador ${ }^{58}$. A su turno, este proceso, con los matices propios de cada área, se deberá hacer sobre cada uno de las siguientes aspectos, según corresponda: (1) financieros, (2) jurídicos, (3) laborales y de recursos humanos, (4) comerciales, (5) de la administración y dirección, (6) pensionales, (7) tributarios, (8) medioambientales, (9) de tecnología de la información y tecnología en general, (10) propiedad intelectual, (11) competencia ${ }^{59}$, y, más recientemente, (12) de cumplimiento o de corrupción y lavado de activos y financiación del terrorismo, y (13) de derechos humanos ${ }^{60}$.

Agotados estos pasos, si la administración de la SPAC y sus accionistas consideran que el negocio que se va a comprar con los recursos captados del público constituye una buena inversión, la empresa pasará a suscribir el contrato de compraventa de acciones, a solicitar y obtener las autorizaciones estatales que fueran del caso, a realizar el pago de las acciones y, en general, a agotar todos los actos necesarios para participar de la empresa que adquirió o con la que se fusionó en los términos previstos. Esta última etapa del negocio se suele denominar fase de finalización de la transacción y usualmente toma un periodo aproximado de 6 meses (desde la fecha de suscripción del contrato hasta la fecha de cierre o closing $\left.{ }^{61}\right)$.

\section{E) Beneficios y retos de las SPAC}

Acudir a una SPAC como un mecanismo de financiación a través de la emisión de acciones en el mercado público de valores tiene varios beneficios y retos. Dentro de los primeros resulta interesante mencionar algunos, como son los siguientes:

58 Sobre la estructura general del reporte de debida diligencia, véase Stefano Gatti, Project finance in theory and practice: Designing, structuring, and financing private and public projects (Nueva York: Elsevier Science \& Technology, 2018): 344-346

59 Peter Howson, The Essentials of M\&A Due Diligence, (Nueva York: Routledge, 2018), 21, 35, 42, 56, $66,73,78,90,96,102,106$ y 111 .

60 Vera Rusinova y Sergey Korotkov, "Mandatory corporate human rights due diligence models: Shooting blanks?", Higher School of Economics Research Paper, n. ${ }^{\circ}$ WP BRP 99/LAW/2021, (2021): 7, https://dx.doi.org/10.2139/ssrn.3849978.

61 Alexandra Reed Lajoux y Capital Expert Services, LLC, The Art of M\&A (Nueva York: McGraw-Hill Professional Publishing, 2019), 747-788. 
1. Las acciones adquieren liquidez y estatus al estar listadas en bolsas de valores y sistemas transaccionales de negociación públicos ${ }^{62}$, los cuales suelen ser NYSE o Nasdaq para el caso de Estados Unidos.

2. Se crea un sentimiento de protección a los inversionistas, debido a que los fondos captados se encuentran en una cuenta fiduciaria o de depósito, cuya finalidad está afecta al proceso de fusión o adquisición respectivo ${ }^{63}$.

3. Se concede el derecho a los accionistas que no aprueben la decisión de fusión o adquisición de retirarse de la empresa a cambio del reembolso de su aporte ${ }^{64}$.

4. Permite a los accionistas adquirir acciones adicionales si se llegare a aprobar una fusión o adquisición exitosa ${ }^{65}$.

5. Reúne a profesionales expertos, quienes se encargan de la administración de la sociedad y de buscar opciones de negocio sin recibir remuneración sino hasta la culminación del negocio ${ }^{66}$.

6. Tiene un límite de tiempo, que por lo general va de 18 hasta a 36 meses.

7. Cuentan con un gran respaldo en dinero en efectivo y permiten el reembolso de dicho dinero a los inversionistas si se oponen a la transacción ${ }^{67}$.

8. Conceden a las compañías objeto de la transacción una liquidez continua, pues aun después de la fusión o adquisición la empresa seguirá cotizando en bolsa ${ }^{68}$.

9. Las empresas que se unen luego de la emisión como resultado del proceso de De-SPAC quedan con un alto grado de liquidez, pues esos recursos que se encontraban en la cuenta fiduciaria o de depósito pasarán a hacer parte del patrimonio de la sociedad con la que se fusiona la SPAC.

10. Atrae flujos de efectivo, liquidez y, además, un talento humano altamente capacitado y profesional, así como a firmas profesionales expertos y colocadores (underwriters) altamente experimentados ${ }^{69}$.

Finkelstein y Cooper, eds. Advances in mergers and acquisitions, 86.

Finkelstein y Cooper, eds. Advances in mergers and acquisitions, 86.

Finkelstein y Cooper, eds. Advances in mergers and acquisitions, 86.

Finkelstein y Cooper, eds. Advances in mergers and acquisitions, 86.

Finkelstein y Cooper, eds. Advances in mergers and acquisitions, 86.

Lipman, International and US IPO, 204.

Lipman, International and US IPO, 204.

Milan Lakicevic y Milos Vulanovic, "A story on SPACs", Managerial Finance 39, n. 4 (marzo 2013):

5, https://dx.doi.org/10.2139/ssrn.1958238 
11. Tienen algunas ventajas frente a los fondos de capital privado, relacionadas con términos de redención, derechos de voto y honorarios de los directivos ${ }^{70}, y$

12. Los requisitos de revelación de información son mucho más leves.

Por su parte, frente al reciente frenesí de emisiones públicas de valores a través de SPAC, algunos autores ${ }^{71}$ y autoridades de regulación, en especial la SEC, han estudiado los riesgos que impone la implementación de este negocio en la práctica, dentro de los cuales se encuentran los siguientes:

1. La estructura de las SPAC puede generar altos costos de administración o implementación $n^{72}$.

2. Su funcionamiento puede crear incentivos para no actuar en procura del mejor interés de los inversionistas minoritarios, en especial, en consideración a que los principales participantes de estos negocios son grandes inversionistas de capital ${ }^{73}$.

3. Las emisiones primarias de valores a través de una SPAC son mucho más volátiles y tienen un mayor impacto en el "efecto de la incertidumbre de mercado" (VIX) y en la "variación de la prima de riesgo" (VRP) que las ofertas públicas tradicionales, por lo cual, puede existir una prevención por parte de los inversionistas en adquirir los valores emitidos por una SPAC 74 .

4. La posibilidad de rentabilidad en la inversión se encuentra atada al momento en el que se venden las acciones, pues si bien antes de la fusión el precio de estas suele incrementar, en el momento en el que se anuncia la integración el precio de cotización baja considerablemente ${ }^{75}$,

Finkelstein y Cooper, eds. Advances in mergers and acquisitions, 88.

En un estudio realizado sobre 47 SPAC, constituidas entre enero del 2019 y junio del 2020, se muestra con claridad y detalle el comportamiento que pueden llegar a tener este tipo de inversiones. Klausner, Ohlrogge y Ruan, "A sober look at SPACs", 3.

Klausner, Ohlrogge y Ruan, "A sober look at SPACs", 3.

Klausner, Ohlrogge y Ruan, "A sober look at SPACs", 3.

Esos fueron los resultados obtenidos en una investigación realizada sobre el comportamiento de 441 SPAC constituidas entre el 2003 y el 2019. Magnus Blomkvist y Milos Vulanovic, "SPAC IPO waves", Economics Letters 197 (diciembre 2020): 3-7. https://doi.org/10.1016/j.econlet.2020.109645

Para ilustrar este punto, el autor de este artículo invirtió en Stable Road Acquisition Corp. (SRAC), una SPAC constituida para la adquisición de empresas de cannabis, a través de la plataforma Charles Schwab. La compra se realizó el 24 de diciembre del 2020 por un valor de 18,8 dólares por acción. La venta se hizo el 9 de febrero del 2021 por un valor de 27,25 dólares por acción. Dicha venta, que se realizó antes de que se anunciara la fusión de SRAC con su objetivo, generó una rentabilidad de 
generando que los inversionistas de largo plazo pierdan un monto importante de su capital ${ }^{76}$.

5. Debido a su estructura, es posible que a fusión genere una gran dilución del capital y exija un aporte adicional por parte de los inversionistas que no resulte atractivo para ellos ${ }^{77}, \mathrm{y}$

6. En términos porcentuales, existe una mayor cantidad de "SPAC fallidas" que de "SPAC subsistentes", por lo que existe un mayor grado de exposición al riesgo con este tipo de operaciones ${ }^{78}$.

Aunque pareciera que las SPAC tienen más beneficios que riesgos y desafíos, lo cierto es que estos últimos, aunque pocos, son de una relevancia mayúscula, pues se relacionan con los aspectos más trascendentales de este tipo de operaciones, como son, la rentabilidad de la inversión, su administración, la dilución del capital y los incentivos de los administradores y patrocinadores. Por ello, en el análisis de la estructuración de este tipo de mecanismos se deben tener en cuenta, tanto sus numerosos beneficios, como sus potenciales y profundos riesgos.

\section{Las SPAC en Colombia}

Habiendo explorado el concepto, la historia, el funcionamiento, las características y los beneficios de la SPAC, conviene analizar esta figura bajo la perspectiva de la regulación local del mercado de valores. Para ello, sin pretender analizar todas las discusiones que pueden surgir de la utilización de esta figura en Colombia, se pasará a analizar: (1) si existen las SPAC en el país, (2) qué tipo de sociedades puede o podría ser utilizado en Colombia para crear una SPAC, y (3) qué retos se perciben en el uso de esta figura en un mercado de valores como el colombiano.

valorización del 44,9\% de la inversión, derivada de un incremento de un 31\% en el valor de la acción desde la inversión. Sin embargo, después de que se anunció la fusión, el precio de la acción cayó considerablemente, hasta alcanzar el valor de 10,50 dólares, precio aproximado al cual se cotiza actualmente.

Klausner, Ohlrogge y Ruan, "A sober look at SPACs", 3.

"What you need to know about SPACs - Updated investor bulletin", SEC, 25 de mayo del 2021. https://www.sec.gov/oiea/investor-alerts-and-bulletins/what-you-need-know-about-spacs-inves tor-bulletin 


\section{A) ¿En Colombia existen las SPAC?}

Cuando se analizan este tipo de figuras propias de los mercados extranjeros, lo primero que resulta pertinente indagar es si en Colombia existen equivalentes funcionales de la figura o, cuando menos, instrumentos semejantes a la misma. En la actualidad, se debe advertir que no existe ningún vehículo o figura jurídica en el país que equivalga a las SPAC, o tan siquiera se les asemeje. Esto se debe, entre otras, a (1) la poca profundidad del mercado de valores de renta variable en Colombia, (2) la desconfianza de los ciudadanos frente al mercado público de valores, y (3) la complejidad regulatoria del régimen jurídico de este mercado en el país.

La primera de las razones por las cuales no existen en Colombia las SPAC tiene que ver con la profundidad del mercado de valores en el país. Efectivamente, como se ha puesto de presente desde hace tiempo atrás, y más recientemente desde la Misión del Mercado de Capitales de Colombia del 2019, el mercado de valores colombiano no es tan profundo como sus análogos internacionales ${ }^{79}$. Esa ausencia de profundidad, que es tanto una causa como un efecto producido por la escasa oferta de productos financieros, de compradores y vendedores de valores y de intermediarios y agentes del mercado, es una de las razones por las cuales productos innovadores y extraños a nuestro mercado, como son las SPAC, no son ofrecidos por quienes cuentan con la capacidad de hacerlo.

Cuando se lleva a cabo un barrido de los diferentes intervinientes del mercado primario de renta variable del mercado público de valores en Colombia, se encuentra que ninguno de ellos ofrece o estructura este tipo de transacciones. Veamos. Primero, las sociedades comisionistas de bolsa en el país, que son tan solo son $18^{80}$, no cuentan con productos variados para acudir al mercado público a través de una emisión primaria de acciones, sino que, conscientes de la extrema regulación de este mercado, se dedican a suministrar algunos de los servicios previstos en la legislación financiera colombiana. Este también es el caso de las corporaciones financieras, cuya oferta de productos no incluye la posibilidad de celebrar este contrato como un mecanismo para acudir al mercado público de valores a través de una oferta pública inicial. Al mismo tiempo, los asesores legales y las oficinas de abogados especializadas en el mercado de capitales no cuentan con este producto dentro de sus servicios de asesoría. Esto mismo ocurre con los demás www.urf.gov.co/webcenter/ShowProperty?nodeld=\%2FConexionContent\%2FWCC_CLUSTER119774\%2F\%2FidcPrimaryFile\&revision=latestreleased 
actores que intervendrían en una emisión primaria de valores, quienes no cuentan en su portafolio con este tipo de servicios.

La segunda de las razones por las cuales las SPAC no existen en Colombia tiene que ver con la desconfianza de los ciudadanos y de los inversionistas hacia el mercado público de valores. Esta razón constituye uno de los retos más difíciles de afrontar, a la vez que configura uno de los desafíos que no deberían frenar el desarrollo del mercado de valores. La falta de confianza en los mercados de capitales en el país, en alguna medida, es justificada y se remonta a los múltiples escándalos que han afectado la reputación de este mercado. Sin embargo, como se apreciará más adelante, las situaciones de fraude o estafa en el mercado de capitales desintermediado no debería opacar el valioso trabajo que han hecho la mayoría los intervinientes en el mercado público de valores, el cual debería sobresalir por encima del comportamiento de quienes actúan de mala fe.

Finalmente, la inexistencia de las SPAC en Colombia se debe a la ausencia de una regulación clara, concisa y lo suficientemente estable para llevar a cabo emisiones de acciones a través de estos vehículos. La regulación del mercado de valores en el país, desafortunadamente, es extensa, técnica, dispersa y poco estable. En primer lugar, el régimen jurídico del mercado de capitales es absolutamente regulado, y lo es de manera tan extensa que ni siquiera los asesores jurídicos más especializados y experimentados alcanzan a conocer y comprender en detalle toda la regulación aplicable a esta materia. En segundo lugar, la normativa que le aplica a este sector es altamente técnica y requiere conocimientos especializados que, en muchas ocasiones, hacen más difícil la estructuración de determinados productos y de la prestación de asesoría. En tercer lugar, el régimen jurídico del mercado de valores se encuentra disperso en diferentes normas y, al estar estrechamente interconectado con otros regímenes normativos altamente reglados, reduce los incentivos de innovación debido a un alto riesgo de cumplimiento. Finalmente, el régimen jurídico del mercado público de valores en Colombia se caracteriza por su falta de estabilidad y su modificación frecuente.

Dicho esto, y teniendo presente que las anteriores son tan solo algunas de las razones por las cuales las SPAC no han tenido un lugar en Colombia, se debe preguntar: ¿cuál sería el vehículo legal para llevar a cabo esta actividad?

\section{B) ¿Qué tipo de emisores se pueden emplear para una SPAC en Colombia?}

Cuando se analizan las figuras jurídicas —sociedades, patrimonios autónomos, entidades sin ánimo de lucro, etc. - que pueden emitir valores en el mercado público 
colombiano, se debe tener en cuenta el instrumento de emisión que utilizan en el extranjero y el tipo de valor que estos emiten para constituir una SPAC. Como se precisó, en Estados Unidos las SPAC son corporations, es decir, sociedades de capital que emiten acciones. Al ser así, se podría decir que en Colombia los únicos emisores que podrían constituirse como una SPAC serían las sociedades de capital habilitadas para hacer emisiones de acciones en el mercado público de valores, lo cual implicaría que las únicas que podrían acudir a este mercado como SPAC sean las sociedades anónimas reguladas en el Código de Comercio. Además, al margen de la discusión sobre si las demás sociedades comerciales reguladas en el Código de Comercio pudieran o no emitir valores en el mercado público de valores, se debe decir que la única sociedad en Colombia que cuenta con el carácter típico de capital de las corporations en Estados Unidos son las sociedades anónimas, pues las demás sociedades comerciales en el país son sociedades de personas o híbridas.

Sin embargo, como lo señala con acierto un sector de la doctrina, las sociedades anónimas hoy en día han "corrido la peor de las suertes" 81 y no constituyen un mecanismo societario atractivo para los inversionistas. En efecto, estas sociedades se encuentran plagadas de prohibiciones, formalismos y, añadiríamos, desincentivos para su constitución ${ }^{82}$. Por ello, parecería que las sociedades anónimas no serían el mejor mecanismo para llegar a hacer una emisión de este tipo, sin perjuicio de que eventualmente lo pudieran hacer. Por lo cual, parecería que la sociedad por acciones simplificada (SAS) constituiría el mecanismo más idóneo para realizar este tipo de emisiones en el mercado primario de valores, pues estas sociedades constituyen la única alternativa viable para realizar emisiones de capital como las que tienen lugar en las SPAC.

\section{C) La SAS como instrumento idóneo para constituir una SPAC}

Lo primero que se debe decir es que en la actualidad las SAS no pueden emitir acciones en el mercado público de valores colombiano debido a una prohibición expresa contendida en el artículo 4 de la Ley 1258 del $2008^{83}$. De acuerdo con esta

81 José Miguel Mendoza, “El futuro de la sociedad anónima (I)", Ámbito Jurídico, 5 de noviembre del 2020. https://www.ambitojuridico.com/noticias/columnista-impreso/sociedades-y-economia-solidaria/ el-futuro-de-la-sociedad-anonima-i

El artículo 33 del Proyecto de Ley 413 del 2021 propone una reforma al artículo 4 de la ley 1258 del 2008, de acuerdo con la cual, se permite la emisión de valores por las SAS en el mercado público, su registro en el RNVE y su inscripción en bolsa. Dicho artículo establece lo siguiente: "La sociedad por acciones simplificada, (sic) podrá ser emisor de valores, para lo cual podrán (sic) inscribir sus valores 
norma, las SAS no se pueden inscribir en el Registro Nacional de Valores y Emisores (RNVE) ni cotizar en bolsa sus valores. Sin embargo, a pesar de esta prohibición, la regulación de la SAS y su flexibilidad y simplicidad, hacen de ella un mecanismo idóneo para constituir en Colombia una SPAC.

Teniendo ello presente, se debe analizar: (1) las razones por las cuales la SAS constituye un mecanismo idóneo para realizar tipo de emisiones, y (2) los argumentos y retos que han impedido que las SAS participen del mercado de valores.

\section{Motivos por los cuales las SAS son un mecanismo idóneo para constituir una SPAC}

Como se ha analizado hasta este punto, las SPAC se constituyen como sociedades mercantiles que realizan emisiones de diferentes series y clases de acciones para captar recursos de capital y entrar en una fusión o una adquisición de una empresa en marcha. En la medida en que en Colombia solo existen tres sociedades mercantiles cuyo capital se divide en acciones, solamente estas pueden ser consideradas para constituir una SPAC. A su turno, de estas tres sociedades, solo la SAS parecería contar con las características necesarias para realizar este tipo de emisiones públicas de valores.

Este último tipo societario, aunque difiere de las corporations estadounidenses, constituyen el único modelo asociativo mercantil que cuenta con el potencial de constituirse como una SPAC, si pudiere acudir al mercado de valores. Esto se debe a varias razones, pero fundamentalmente a que las SAS: (1) tienen requisitos de constitución y de funcionamiento más flexibles y fáciles de cumplir que cualquier otro tipo societario en el país; (2) permiten emitir diferentes series y clases de acciones, lo cual resulta un atractivo para constituir una SPAC; (3) han adquirido lo que podría denominarse una madurez institucional ${ }^{84}$, que justificaría que, al igual que sus homólogos híbridos como lo son limited liability company y la société par actions simplifiée, se permita hacer emisiones del mercado público de valores ${ }^{85}$

en el Registro Nacional de Valores y Emisores (RNVE) y negociarlos en bolsas de valores, en los términos y condiciones que determine el Gobierno nacional. Entre estas condiciones se considerarán aspectos relacionados con los estatutos y con el gobierno corporativo de este tipo de sociedades".

Este fue el término empleado por un interviniente ante la Corte Constitucional en la Sentencia C-331 del 2020, por medio de la cual se declaró la constitucionalidad del Decreto 817 del 2020.

85 Se debe aclarar que, a diferencia de lo que ocurre en Francia, en donde las emisiones de la Société par Actions Simplifiée en el mercado público de valores constituye una excepción a la prohibición general, en Estados Unidos no existe una prohibición para emitir acciones públicamente por parte de la Limited Liability Company. En dicho país lo que determina la aplicación del régimen del mercado de valores y el nacimiento del deber de inscripción ante la SEC es la existencia de un valor. En esa 
en alguno casos, y (4) se pueden adaptar a las diferentes requerimientos de una actividad o una empresa.

Estas sociedades, además de rescatar los mejores elementos de las sociedades de capital, son lo suficiente flexibles para adaptarse a necesidades de todo tipo y, en este caso, a los requerimientos propios para constituir una sociedad instrumental como la estudiada ${ }^{86}$. Por este motivo, se podría decir que las SAS son el mecanismo idóneo para constituir una SPAC en Colombia.

\section{Argumentos y retos que han impedido que la SAS participe del mercado de valores}

En diferentes foros de discusión académica se han esgrimido varios argumentos por los cuales se considera que la SAS no debe acudir al mercado público de valores. Entre estas razones, algunas de ellas se orientan a afirmar que: (1) las SAS gozan de una flexibilidad especial que se perdería debido a los requisitos que se exigen en el mercado público de valores; (2) si las SAS se usan en el mercado de valores es posible que pierdan sus características de sociedades híbridas y adquieran matices más propios de sociedades tradicionales; (3) las SAS, tal y como están reguladas en Colombia, tienen un claro antecedente francés de acuerdo con el cual estas sociedades nacieron para fines diferentes a acudir el mercado de valores; (4) las SAS pueden perder su buena reputación debido a los tradicionales escándalos del mercado de valores, y (5) las SAS cuentan con varios mecanismos de capitalización que no hacen necesario acudir al mercado de valores. Sobre el particular, resulta pertinente plantear algunas reflexiones que, sin pretender agotar la discusión de manera exhaustiva, pueden enriquecer el debate sobre la posibilidad de que las SAS acudan al mercado de valores.

En primer lugar, resulta interesante interrogarse en qué medida la regulación bursátil afectaría el marco normativo de la SAS y, por ende, su flexibilidad. En general, se podría decir que la posibilidad de acudir al mercado de valores no altera en ninguna medida la regulación general de las SAS, ya que, si este tipo de sociedad

medida, las cortes estadounidenses son claras al establecer que, siempre y cuando el instrumento emitido constituya un valor, le serán aplicables a dicha emisión las reglas del mercado público de valores y se deberá hacer la inscripción ante la SEC, por lo cual se puede decir que el tipo societario no es el elemento de inflexión, sino la existencia de un valor. Aunque en principio se dice que estas empresas no pueden cotizar en bolsa, recientemente algunas lo han hecho. Mary Siegel, "Publiclytraded LLCs: The new kid on the exchange," SMU Law Review 68, n. ${ }^{\circ} 3,885$.

86 Las SAS pueden ser el vehículo idóneo para estructurar diferentes tipos de mecanismos de financiación, como lo son la project company en project finance, a la cual se denomina comúnmente como special purpose company o special purpose vehicle. 
acude al mercado de capitales des-intermediado, las reglas adicionales que le sean exigibles lo serán por su calidad de emisor público, mas no por el tipo societario respectivo. Para ilustrar este punto, basta tener en cuenta que, en emisiones de entidades sin ánimo de lucro, de sociedades en crowdfunding y de SAS bajo el Decreto 817 del $2020^{87}$, el régimen general del emisor se mantiene inalterado, salvo la imposición de unos requisitos adicionales encaminados a proteger al inversionista.

En segundo lugar, cuando se analiza la pérdida de las características híbridas de las SAS, se debe cuestionar (1) si con la regulación adicional la SAS pierde su naturaleza híbrida, y (2) si dicha naturaleza es valiosa per se, o si lo es por el uso práctico que se le pueda dar a la sociedad. Sobre el primero de los interrogantes se debe decir que no parecería existir una razón evidente para creer que la regulación especial del mercado de valores modifique el régimen general de las SAS, por lo cual, estas no alterarían su naturaleza híbrida. Sobre el segundo punto, podría decirse que las sociedades híbridas son el resultado de una necesidad planteada por el comercio que derivó en la creación de un modelo asociativo flexible que reuniera algunos de los rasgos propios de las sociedades personales y de capital. En esa medida, si se tiene presente que las sociedades híbridas nacieron con el objetivo de dar solución a una problemática derivada de la poca flexibilidad de los tipos societarios existentes en su momento, se debería concluir que dicha naturaleza no riñe con la posibilidad de acudir al mercado de capitales como emisores de valores.

En tercer lugar, se debe tener presente que la SAS colombiana tiene un antecedente francés en la Ley 94-1 del 3 de enero de $1994^{88}$, que creó este tipo asociativo en el país galo y adicionó la Ley 66.537 del 24 de julio de $1966^{89}$, que regulaba hasta entonces las sociedades comerciales en Francia. Dicha norma, en su artículo 262-3, establecía una restricción frente a la utilización de los valores emitidos por la SAS como instrumentos para captar el ahorro del público, al mencionar que: "[I]a sociedad por acciones simplificada no puede acceder públicamente al ahorro"${ }^{90}$. Esta prohibición, que se mantiene en la actualidad ${ }^{91}$, se comprende más profundamente cuando se analizan los reportes elaborados por la Asamblea Nacional

A la fecha de este artículo, bajo ese decreto, solamente se ha hecho una emisión de valores por parte de una SAS, cual fue la hecha por Inverfam S. A. S. y consistió en una colocación de bonos garantizados por el Fondo Nacional de Garantías S. A.

Loi no 94-1 du 3 janvier 1994 instituant la société par actions simplifiée. Loi no 66-537 du 24 juillet 1966 sur les sociétés comerciales.

90 La versión original establece: "La société par actions simplifiée ne peut faire publiquement appel à l'épargne". 
durante los debates sostenidos para aprobar dicha ley. En estos se percibe que, si bien las SAS no fueron pensadas como instituciones para la emisión pública de valores per se, el motivo que inspiró dicha restricción obedecía a preocupaciones de solvencia que presentaba la asamblea en su momento. En dichos reportes se percibe que la precaución del legislador francés frente a la captación de dineros del público se relacionaba con la solvencia de las $\mathrm{SAS}^{92}$ y con elementos intuitus personae que estaban presentes en dicha institución ${ }^{93}$, mas no en otra razón. Esta previsión, hoy contenida en el artículo L227-2 del actual Código de Comercio francés, sería la que inspiraría al legislador colombiano a establecer la prohibición contenida en el artículo 4 de la Ley 1258 del 2008.

Sin embargo, se debe decir que las razones por las cuales en Francia no se previó la posibilidad para que las SAS emitieran sus valores en bolsa se derivaban del contexto mercantil y empresarial concreto, el cual difería de aquel que atravesaba Colombia en el momento de la promulgación de la ley de SAS. Por ello, desde el punto de vista histórico, no existiría una razón para trasladar esta prohibición a Colombia.

En cuarto lugar, sería oportuno reflexionar si la inscripción de una SAS en bolsa puede afectar su reputación, en especial, teniendo en cuenta los casos de fraude que se han presentado en el mercado bursátil colombiano. Sobre el particular, bastaría con señalar que la reputación de una institución jurídica no se afecta, per se, por el buen o mal uso que se haga de ella. Además, podría decirse que, inclusive cuando una institución se usa en contra de la ley, si el sistema jurídico cuenta con marcos regulatorios fuertes o con autoridades de supervisión diligentes, como lo es la Superintendencia Financiera de Colombia, la figura jurídica mantiene su valor y reputación a pesar de dicho uso. Un ejemplo claro de esta situación se presentó en 1980, cuando Onnix Financial Group, Inc., una firma de valores de Estados Unidos, utilizó de manera fraudulenta el denominado en inglés penny stock market ${ }^{94}$. En ese caso, a pesar del uso de la regulación de este mercado en perjuicio

92 "Por el contrario, el Senado había estimado indispensable elevarlo [el capital mínimo de constitución] de manera significativa para dotar a las S. A. S. de una base financiera suficiente y adecuada para su objeto. Fijándole a estas dos veces el mínimo [de capital] aplicable a las sociedades que acuden al ahorro del público, es decir, tres millones de francos, había deseado igualmente disuadir a los grupos de utilizar esta nueva forma societaria para llevar a cabo sus proyectos más riesgosos". Traducción libre del autor. Rapport n. ${ }^{0} 35$ del Senado de la Asamblea Nacional del 14 de octubre de 1993, 18.

93 “Este artículo [262-3] prohíbe a las S. A. S. acudir públicamente a los ahorros del público. Asegura el carácter cerrado de esta sociedad, caracterizada por la regla de la unanimidad y por un elemento intuitu personae muy fuerte". Traducción libre del autor. Rapport n. 35 del Senado, 18. 
de determinados inversionistas, el sistema mantuvo su reputación y, hoy en día, sigue siendo uno de los mercados más atractivos para algunos inversionistas.

Además, el riesgo de fraude o de abuso del derecho podría reducirse a través de una regulación que incentive al buen funcionamiento de estas empresas desde el punto económico. Así, si se pensare, por ejemplo, en la necesidad de que las SAS acudieran al mercado público a través del contrato de underwriting en firme, se estaría controlando el riesgo de fraude o abuso a través de incentivos de mercado. Al imponer una restricción de este tipo, serían las instituciones financieras quienes inicialmente controlarían el acceso al mercado, pues las sociedades colocadoras solo estarían dispuestas a hacer underwriting en firme de valores de empresas con un respaldo y una transparencia determinadas.

Finalmente, se ha afirmado que las SAS cuentan con amplios y variados mecanismos de financiación que hacen innecesario exponerlas a los riesgos propios de la financiación a través del mercado público de valores. Aunque es cierto que las SAS cuentan con varios mecanismos de capitalización, este no constituye un argumento suficiente para privar a las personas de utilizar a este tipo de sociedades

para diferentes objetivos, por supuesto, siempre dentro del marco de la legalidad y de los límites de la libre autonomía de la voluntad.

De manera que, si bien las SAS hoy en día no pueden cotizar en bolsa, y ello impide que estas se utilicen para constituir una SPAC y hacer una emisión de valores en el mercado primario, lo cierto es que las SAS pueden llegar a ser el mecanismo idóneo para implementar esta figura en Colombia ${ }^{95}$.

\section{D) Retos de la utilización de una SPAC en Colombia}

Teniendo presente lo dicho hasta el momento, resulta pertinente identificar algunos de los desafíos que surgen cuando se estudia la posibilidad de acudir a las SPAC como un mecanismo de financiación a través de una emisión pública inicial en el mercado público de valores. A continuación, se ponen de presente algunos de esos retos.

El primer desafío que enfrenta una empresa que quiera acudir a este mecanismo de financiación consiste en la necesidad de tener que constituirse como una sociedad anónima. Este reto constituye un impedimento importante, puesto

Coincidimos con el profesor Francisco Reyes cuando afirma "[...] en el momento actual de la evolución de este tipo de sociedad [SAS] en Colombia justifica su acceso al mercado bursátil, siempre y cuando se provean algunas salvaguardias mediante las cuales se brinden garantías suficientes a los inversionistas". Francisco Reyes Villamizar, Derecho societario, tomo I (Bogotá: Temis, 2020), 916. 
que, además de sujetar el acceso a este mercado al uso de este tipo societario tan restringido y ritualista, con ello se priva al estructurador de la SPAC de aprovechar la libertad de configuración de otros tipos societarios más flexibles, como las SAS. Bajo esa idea, el promotor de la SPAC y sus estructuradores no podrían realizar emisiones con diferentes matices, como lo podrían ser la emisión de distintas series y clases de acciones, lo cual es común que se haga en las SPAC, sino que tendrían que ajustarse a los rígidos moldes de la sociedad anónima, y empeñarse en que el negocio sea atractivo, a pesar de las restricciones que impone este tipo de sociedad.

El segundo reto que parecería evidente en una emisión de valores bajo la regulación financiera colombiana se encuentra en el Decreto 2555 del 2010. El artículo 5.2.1.1.3 de esta norma, que regula los requisitos para la inscripción de emisiones y emisores en el RNVE, establece en su literal i) la necesidad de acompañar la solicitud de inscripción del estudio de factibilidad económica, financiera y de mercado del emisor, si este se encuentra en etapa preoperativa o tiene menos de dos años de haber iniciado operaciones. Esta norma parecería ser aplicable a las SPAC, a pesar de que estas no inician su operación en estricto sentido sino hasta después de la oferta pública inicial de valores. Por ello, la SPAC tendría que presentar dicho estudio si quiere realizar una emisión primaria de acciones. Esta exigencia constituiría un reto para la sociedad, no solo por la elaboración misma del estudio en consideración a la naturaleza instrumental de la compañía, sino también frente a la aceptación de la autoridad de supervisión sobre dicho análisis.

El tercer obstáculo que se puede presentar tiene que ver con el prospecto de información y las características que son exigibles del mismo en una emisión primaria de acciones. En efecto, los requisitos que se exigen en este prospecto por el Decreto 2555 del 2010, y por la parte III, título I, capítulo II de la Circular Básica de la Superintendencia Financiera de Colombia, pueden llegar a constituir un reto adicional. En esas dos normas, especialmente en la segunda, se encuentran algunas exigencias que no parecería claro cómo se podrían cumplir en el caso de una SPAC. Así, por ejemplo, el artículo 1.3.6.1.1.18.3 de dicha circular impone la obligación de señalar la "[a]ctividad principal, breve reseña histórica de la entidad y datos sobre la conformación de la entidad", al paso que el artículo 1.3.6.1.1.18.6 de la misma exige "[c]opia del último estado financiero de propósito general de fin de ejercicio, junto con el informe presentado por el auditor del garante sobre dicho estado financiero, acompañado de sus respectivas notas explicativas". Como se puede apreciar, una SPAC típicamente no podrá dar una reseña histórica de esta, pues se constituye para solamente con el fin de realizar la emisión. Al mismo 
tiempo, la sociedad podría no contar con esos estados financieros de propósito general, pues en ocasiones la SPAC se constituirá y buscará realizar la emisión pública antes de completar su primer ejercicio.

Un cuarto de punto de reflexión sobre los retos de la incorporación de esta figura al derecho nacional tiene que ver con la recepción social que tenga por parte de los intervinientes del mercado de valores. Para que estas figuras sean exitosas en Colombia y contribuyan a la profundización del mercado de valores, debe existir una acogida por parte de quienes intervendrían en una estructuración como la propuesta, dentro de los cuales se cuentan: (1) a las sociedades comisionistas de bolsa, las corporaciones financieras y demás agentes colocadores o que hacen underwriting; (2) a los inversionistas; (3) a las sociedades fiduciarias, quienes administrarían los recursos de la captación de acuerdo con el contrato celebrado con el constituyente, que sería la SPAC; (4) a la BVC, quien sería el proveedor de infraestructura y el administrador de la plataforma transaccional, debido a que es el único administrador de sistemas de negociación de renta variable en el país; y (5) las autoridades de supervisión y regulación.

Finalmente, se debería tener en cuenta el riesgo y la acogida del producto por parte de los inversionistas en consideración al mismo. Particularmente, se debe analizar si este instrumento puede llegar a ser más atractivo que sus alternativas, como, por ejemplo, los leveraged buyouts, en los cuales la financiación se basa principalmente en deuda ${ }^{96}$, pero en los cuales no parecerían existir los riesgos de las SPAC. En esa misma línea, se tendría que analizar si las dificultades que se han identificado en los regímenes de derecho anglosajón se comparten en Colombia, en especial, aquellas relacionadas con el valor de las acciones después de anunciada la fusión, la dilución del capital invertido, la creación de incentivos en cabeza de la administración, y los costos de administración y de manejo de la SPAC.

\section{Conclusiones}

Teniendo en cuenta el estudio presentado sobre el uso potencial de las SPAC en el mercado público de valores colombiano, y conscientes que la discusión sobre las ventajas y desventajas del uso de un instrumento de este tipo en Colombia goza 
de múltiples matices que van más allá del alcance de presente escrito, se pueden extraer cuatro conclusiones fundamentales de lo dicho hasta este punto.

En primer lugar, se debe concluir que la SPAC constituye un instrumento innovador que contribuye a la financiación alternativa de proyectos en el país y que ayuda a la profundización del mercado de capitales a través de la estructuración de proyectos que impactan diferentes sectores de la economía. El uso de este tipo de sociedades instrumentales constituye una vía idónea para recibir financiación en el mercado de valores, para realizar inversiones en proyectos con alta rentabilidad, para canalizar dichos recursos a otros sectores de la economía a través de fusiones y adquisiciones de empresas cerradas y, así mismo, para profundizar el mercado de capitales des-intermediado a través de la creación de mecanismos de inversión que requieran de la contribución de varios intervinientes del mercado de capitales.

En segundo lugar, puede concluirse que las SPAC son instrumentos que tienen la vocación de contribuir a diferentes sectores de la economía a través de la canalización de recursos de capital y de talento humano. En la medida en que la finalidad última de las SPAC consiste en realizar emisiones públicas de valores para captar dinero y con este entrar en un proceso de fusión o adquisición con empresas cerradas que cuentan con un negocio en marcha, esta figura tiene el potencial de generar un gran impacto en otros sectores de la economía. Así, en la medida en que los recursos de capital y parte del talento humano de la SPAC se unen con la sociedad objetivo, se podría decir que este mecanismo de financiación puede llegar a tener un gran impacto en los sectores primario, secundario, terciario y cuaternario de la economía.

En tercer lugar, se debe concluir que en Colombia las SPAC no existen hasta la fecha y que, con la oferta actual de tipos societarios del país, su estructuración presentaría un reto difícil de afrontar. Si bien en principio se podría afirmar que las sociedades anónimas y las SAS son tipos asociativos por medio de los cuales se podría estructurar una SPAC, lo cierto es que cada una de ellas cuenta con impedimentos que hoy en día hacen que no sean ideales para estructurar este tipo de negocio. En el caso de la sociedad anónima, su regulación rígida y anacrónica la convierte en un instrumento poco atractivo para constituir una SPAC. En las SAS, por el contrario, el impedimento fundamental viene dado por la imposibilidad legal de realizar emisiones públicas de valores, la cual se deriva de una prohibición para que las SAS inscriban sus valores en al RNVE y en las bolsas de valores.

Finalmente, se debe concluir que se existen varios retos cuando se analiza la introducción de las SPAC en Colombia, los cuales se relacionan principalmente con el régimen societario nacional, el régimen del mercado de valores colombiano y la 
aceptación que pueda tener la figura entre los intervinientes en el mercado público de valores en el país. Asimismo, existen toda una serie de desventajas relacionadas con el funcionamiento en el mercado de las SPAC, en especial, en lo que tiene que ver con la dilución del capital social, la creación de incentivos indeseados para los administradores y las posibilidades de utilidad de acuerdo con el momento de liquidar la inversión. Todas estas dificultades quedan planteadas para el debate que se abre sobre el uso de esta figura en Colombia.

\section{Referencias}

"Alec Gores strikes again with biggest SPAC merger to date". PitchBook, https://pitchbook.com/news/articles/gores-group-biggest-spac-merger

"Amendment No. 2 to Form S-1 under the Securities Act of 1933". U. S. Securities and Exchange Commission. https://www.sec.gov/Archives/ edgar/data/1754824/000161577418013897/s114444_sla.htm

Asamblea Nacional de Francia. Rapport n. ${ }^{\circ} 35$ del Senado de la Asamblea Nacional del 14 de octubre de 1993.

"Blank check company". U.S. Securities and Exchange Commission. https://www.investor.gov/introduction-investing/investing-basics/ glossary/blank-check-company.

Blomkvist, Magnus y Milos Vulanovic. "SPAC IPO waves". Economics Letters 197 (diciembre, 2020): 1-11. https://doi.org/10.1016/j.econlet. 2020.109645

"Comisión de las Comunidades Europeas". EUR-Lex. https://eur-lex.eu ropa.eu/LexUriServ/LexUriServ.do?uri=COM:2009:0226:FIN:ES:PDF

Corte Constitucional de Colombia. Sentencia C-331 de 2020, M. P. José Fernando Reyes Cuartas.

"David Alan Miller". Graubard Miller. https://www.graubard.com/attor ney/miller-david-alan/

Decreto 2555 del 2010, 15 de julio, Diario Oficial 47.771.

Decreto 817 del 2020, 4 de junio, Diario Oficial 51.335.

Decreto 1068 del 2020, 23 de julio, Diario Oficial 51.384.

Decreto 1235 del 2020, 14 de septiembre, Diario Oficial 51.437. 
Feldman, David N. Regulation A+ and other alternatives to a traditional IPO: Financing your growth business following the JOBS act. Hoboken, New Jersey: John Wiley \& Sons, 2018.

-. Reverse mergers: And other alternatives to traditional IPOs. Nueva York: John Wiley \& Sons, 2009.

Finkelstein, Sydney y Cary L. Cooper (eds.). Advances in mergers and acquisitions. Bingley: Emerald Publishing Limited, 2017.

Gatti, Stefano. Project finance in theory and practice: Designing, structuring, and financing private and public projects. Nueva York: Elsevier Science \& Technology, 2018.

Gaughan, Patrick A. Mergers, acquisitions, and corporate restructurings. Hoboken: John Wiley \& Sons, Incorporated, 2018.

"Greenshoe option". Investopedia. https://www.investopedia.com/ter $\mathrm{ms} / \mathrm{g} / \mathrm{greenshoe.asp}$

Heyman, Derek K. "From blank check to SPAC: The regulator's response to the market, and the market's response to the regulation". Ohio State Business Law Journal 2, n. ${ }^{\circ}$ (2007): 531-552. http://hdl.handle. net/1811/78301

Hinestrosa, Fernando. Tratado de las obligaciones II. Negocio jurídico I. Bogotá: Universidad Externado de Colombia, 2015.

Howson, Peter. The essentials of M\&A due diligence. Nueva York: Routledge, 2018.

Humberto Martínez, Néstor. Cátedra de sociedades. Régimen comercial y bursátil. Bogotá: Legis, 2020.

Klausner, Michael D., Michael Ohlrogge y Emily Ruan. "A sober look at SPACs". European Corporate Governance Institute-Finance Working Paper, n.o 746/2021 (abril 2021): 1-57. https://dx.doi.org/10.2139/ ssrn.3720919

Kumar, Vinod y Priti Sharma. An insight into mergers and acquisitions: A growth perspective. Singapur: Springer Singapore Pte. Limited, 2019.

Lakicevic, Milan y Milos Vulanovic. "A story on SPACs". Managerial Finance 39, n. 4 (marzo 2013): 1-37. https://dx.doi.org/10.2139/ssrn. 1958238

Ley 964 del 2005, 8 de julio, Diario Oficial 45.963.

Ley 1955 del 2019, 25 de mayo, Diario Oficial 50.964.

Lipman, Frederick D. International and US IPO planning: A business strategy guide. Hoboken: John Wiley \& Sons, Incorporated, 2008. 
Mascareñas, Juan. "Compañía de adquisición de propósito especial (SPAC)", Monografías de Juan Mascareñas sobre Finanzas Corporativas (abril 2021): 1-24. https://dx.doi.org/10.2139/ssrn.3824785

Mendoza, José Miguel. "El futuro de la sociedad anónima (I)". Ámbito Jurídico, 5 de noviembre del 2020. https://www.ambitojuridico.com/ noticias/columnista-impreso/sociedades-y-economia-solidaria/el-futu ro-de-la-sociedad-anonima-i

Mendoza, José Miguel. "Securities regulation in low-tier listing venues: The rise of the alternative investment market". Fordham Journal of Corporate \& Financial Law 13, n. ${ }^{\circ} 2$ (2008), 258-328. https://ssrn.com/abs tract $=1004548$

Moreno Jaramillo, Andrés. La bolsa en Colombia en el siglo XXI. Bogotá: Andrés Moreno Jaramillo, 2020.

Muñoz, Diego. Privatización en Colombia: marco jurídico para la transferencia de la propiedad estatal. Bogotá: DNP, 2004.

Palmiter, Alan R. Securities regulation. Examples \& explanations. Nueva York: Wolters Kluwer, 2017.

"Principals". EarlyBirdCapital. https://www.earlybirdcapital.com/about/ principals

"Private equity purchasers and SPACs may be 'preferred' divestiture buyers under new DOJ guidelines for merger remedies". The National Law Review. https://www.natlawreview.com/article/private-equity-purcha sers-and-spacs-may-be-preferred-divestiture-buyers-under-new

Proyecto de Ley 413 del 2021, Congreso de la República.

Ramey Layne y Brenda Lenahan, Vinson \& Elkins LLP. "Special purpose acquisition companies: An introduction". The Harvard Law School Forum on Corporate Governance. https://corpgov.law.harvard.edu/2018/07/06/ special-purpose-acquisition-companies-an-introduction

Reed Lajoux, Alexandra y Capital Expert Services, LLC. The art of M\&A. Nueva York: McGraw-Hill Professional Publishing, 2019.

"Regulatory notice 08-54. Guidance on special purpose acquisition companies". Finra. https://www.finra.org/rules-guidance/notices/08-54

Reyes Villamizar, Francisco. Derecho societario, tomo I. Bogotá: Temis, 2020.

Riemer, Daniel S. "Special purpose acquisition companies: SPAC and span, or blank check redux". Washington University Law Review 85, n. 4 (2007): 931-968. 
Rose, Paul y Steven Davidoff Solomon. "Where have all the IPOs gone: The hard life of the small IPO". Harvard Business Law Review 6, n. 1 (Winter 2016): 83-128.

Rusinova, Vera y Sergey Korotkov. "Mandatory corporate human rights due diligence models: Shooting blanks?". Higher School of Economics Research Paper, n. ${ }^{\circ}$ WP BRP 99/LAW/2021, (2021): 2-25. https://dx.doi. org/10.2139/ssrn.3849978

Siegel, Mary. "Publicly-traded LLCs: The new kid on the exchange". SMU Law Review 68, n. ${ }^{\circ} 3$ (2015): 885-898. https://scholar.smu.edu/smulr/ vol68/iss $3 / 25$

"SPACDex: Market cap \& equal weighted return". SPACInsider. https:// spacinsider.com/stats/

"SPAC IPOs in the U.S. 2009-2021". Statista. https://www.statista.com/ statistics/1178249/spac-ipo-usa/

"SPACs have raised $\$ 40$ billion in dry powder, and it's growing daily". RBC Capital Markets. https://www.rbccm.com/en/gib/ma-inflection-points.page

Superintendencia de Sociedades. Concepto 220-056752 del 29 de marzo del 2016.

Superintendencia de Sociedades. Oficio 220-046656 del 16 de mayo del 2019.

"Term sheet overview". Corporate Finance Institute. https://corporatefi nanceinstitute.com/resources/templates/transactions/term-sheet-guide/

"The king of SPACs wants you to know he's the next warren buffett". Bloomberg, 12 de febrero de 2021. https://www.bloomberg.com/news/ articles/2021-02-12/the-king-of-spacs-wants-you-to-know-he-s-thenext-warren-buffett

Van Rensburg, Johnny y Gary van Vuuren. "Evaluating investment decisions based on the business cycle: A South African sector approach". Cogent Economics \& Finance 8, n. ${ }^{\circ} 1$ (2020): 1-24. https://doi.org/10.108 $0 / 23322039.2020 .1852729$

Varón Palomino, Juan Carlos. "Cartas de intención, memorandos de entendimiento, acuerdos de confidencialidad y acuerdos de debida diligencia, como fuentes de obligaciones en Colombia: apuntes desde la teoría del acto o negocio jurídico y de la formación del contrato". Anuario de Derecho Privado, n. ${ }^{\circ}$ (2019): 153-184. http://dx.doi.org/10.15425/2017.200

"What you need to know about SPACs-Updated investor bulletin". U.S. Securities and Exchange Commission. https://www.sec.gov/oiea/investor-alerts -and-bulletins/what-you-need-know-about-spacs-investor-bulletin 